\title{
Solvent Free Synthesis of Biscoumarins
}

\author{
Mahesh Chand* \\ *Department of Chemistry, University of Delhi, India
}

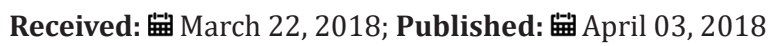

*Corresponding author: Mahesh Chand, Department of Chemistry, University of Delhi, Delhi-110007, India, Email: mahesh.chand2008@gmail.com

\begin{abstract}
Coumarin and Coumarin-related compounds are major source of interest for many of medicinal chemist to explore its various pharmacological potentials especially bis-coumarin for their anticoagulant activity. A number of reports have appeared in the literature on the enhancement of bioactivity of bis heterocyclic compounds over simple heterocyclic compounds. Biscoumarin are very well known and possess better biological activities like anticoagulant, anti oxidant, antimicrobial activity, anti cancerous and analgesic activity than the parent nuclei. Hence, realizing the importance of biscoumarin, we thought to summarize the synthesis of bis-coumarins under solvent-free conditions in this review.
\end{abstract}

\section{Introduction}

Coumarins are widespread in nature and have been reported to possess various biological and/or pharmacological properties. They are known to possess antibacterial, inhibitory activity on platelet aggregation, antiallergic, anti-inflammatory, antioxidant, anti insecticidal, antiviral, anticoagulant, anticancer, antifungal, anti-HIV and antibiotics. Coumarin [1] is a simple molecule and many of its derivatives have been known for more than a century [1] (Figure 1). Coumarins have multiple biological activities including disease prevention, growth modulation and anti-oxidant properties.

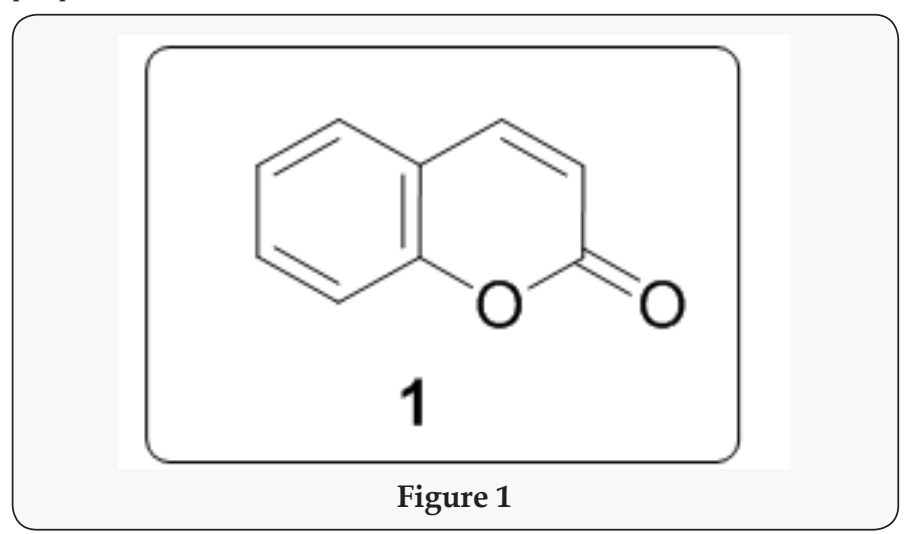

Bis heterocyclic compounds also constitute an important class of biologically active molecules. Expected to possess enhanced bioactivity and could also be explore as important intermediates for constructing new molecules. Biscoumarin is among one of bis heterocyclic in literature which have shown lot of biological applications.
3,3'-Methylene bis(4-hydroxycoumarin) commonly known as dicoumarol [2], occurs naturally and is the hemorrhagic agent responsible for sweet clover disease of cattle and has also been employed for the prevention and treatment of thrombosis [2] (Figure 2).

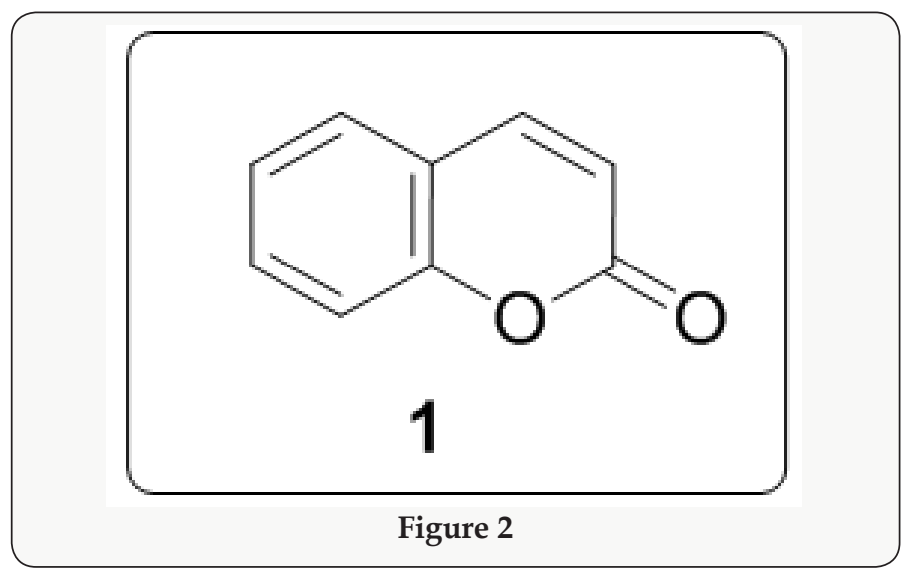

Dicoumarol is also the starting material for the synthesis of furocoumarins and benzopyrans [3]. 3, 3-(4-Arylmethylene) bis(4-hydroxycoumarins), commonly known as biscoumarins, which are the bridged substituted dimmers of 4-hydroxy Coumarin, have enormous potential as anticoagulants. Coumarin have become the research hot point based on their different pharmalogical profiles specially biscoumarin. Herein, we have made efforts to summarize the synthesis of bis (Coumarin) methane's in solvent free conditions because solvent-free synthesis is gaining importance as a tool for the synthesis of a wide variety of useful and important compounds, 
with the number of reactions conducted under these conditions increasing.

\section{Solvent free synthesis of biscoumarins}

One pot synthesis of bis (4-hydroxycoumarin)methane's using manganese chloride $(\mathrm{MnCl} 2.4 \mathrm{H} 2 \mathrm{O})$ as an efficient catalyst in water [4] (Figure 3). Synthesis of biscoumarin derivatives in ionic liquids [5] (Figure 4). Synthesis of biscoumarins from aldehydes and 4-hydroxycoumarin in the presence of catalytic amount of silica supported Preyssler nanoparticles. They immobilized H14[NaP5W300110] into the SiO2 nanoparticles and investigated the catalytic behavior of this as catalyst during biscoumarins formation [6] (Figure 5). Biscoumarins was prepared in one pot domino Knoevenagel condensation/Michael reaction between 4-hydroxycoumarin and aldehydes by using phosphotungstic acid [7] (Figure 6). Biscoumarins was prepared in one pot domino Knoevenagel condensation/Michael reaction between 4-hydroxycoumarin and aldehydes by using phosphotungstic acid [7] (Figure 6).

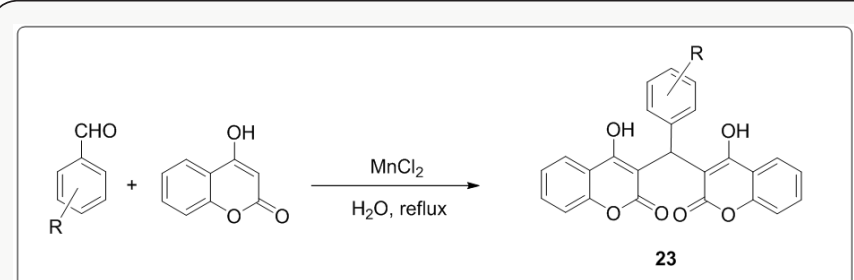

Figure 3

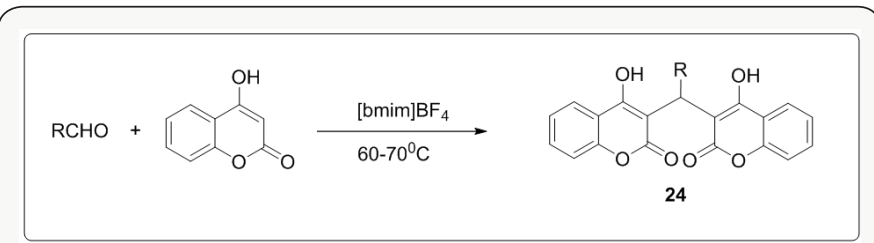

Figure 4

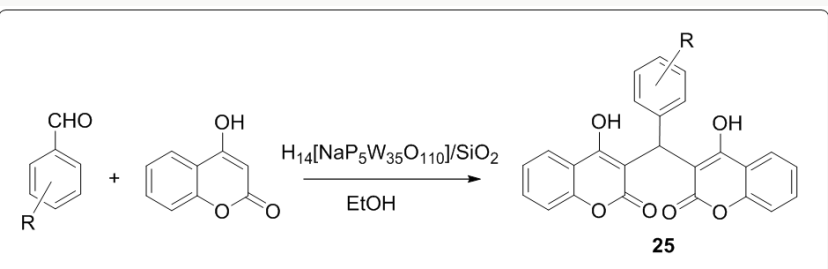

Figure 5

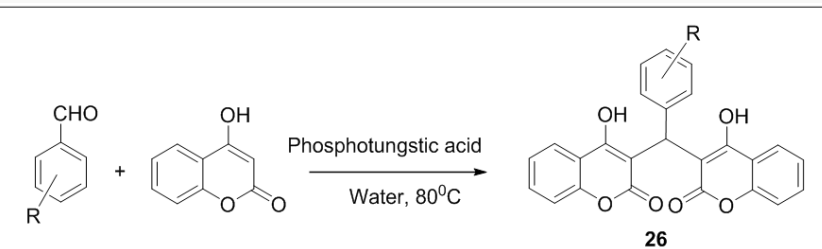

Figure 6
Synthesis of biscoumarins by the reaction of aldehydes and 4-hydroxycoumarin in water under reflux in presence of TBAF or $\mathrm{LiBr}$ or $\mathrm{NH} 4 \mathrm{Cl}$ or $\mathrm{NH} 2 \mathrm{SO} 3 \mathrm{H}$ or pTSA as the catalyst [8]. Synthesis of biscoumarins has also been reported by heating the components in presence of ethanol or under neat conditions [9] (Figure 7). Recently, we have reported the Knoevenagel condensation of aldehydes with barbituric acids catalyzed efficiently by PVP stabilized Ni (0) nanoparticles in ethylene glycol [10]. Since, one of the prime steps in the synthesis of tetraketones and biscoumarins is the Knoevenagel condensation of aldehydes with dimedone or 4-hydroxycoumarin; therefore, we envisaged the application of nickel nanoparticles for the synthesis of tetraketones and biscoumarins. The chemical and biological studies were carried out of the properly substituted benzylidene-bis-(4-hydroxycoumarin) derivatives and 3-(6-oxo (1H)-benzopyrano[4,3-b]benzopyran-7-yl)-4-hydroxycoumarin derivatives[11]. The preparation of biscoumarins was carried out in water by using $\mathrm{RuCl} 3 \bullet \mathrm{nH} 2 \mathrm{O}$ which provides the desired products in short reaction times and high yields [12] (Figure 8).

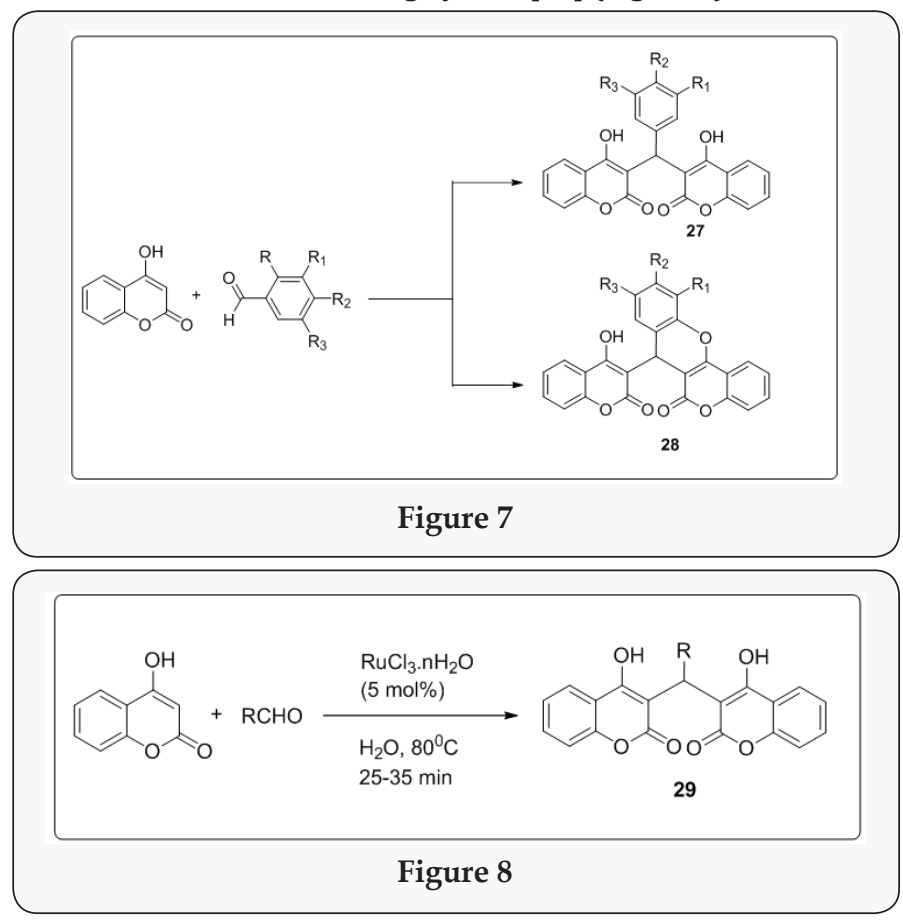

The synthesis of 2,2-aryl-methylene,bis(3-hydroxy-2-cyclohexene-1-one), also known as biscoumarins via Knoevenagel condensation followed by rapid Michael addition by using polyvinyl pyrrolidone (PVP) stabilized nickel nanoparticles as a catalyst for promoting [13] (Figure 9). A simple, one-pot, pseudo three-component reaction between various arylaldehydes and 4-hydroxycoumarin for the synthesis of biscoumarin derivatives using phosphosulfonic acid as a reaction mediator under solvent-free neat conditions in good to excellent yields [14] (Figure 10). In the frame of research that examines the use of task-specific ionic liquids (ILs) for developing green methodologies toward novel bioactive compounds, ethanolamine-derived ILs were synthesized and used as solvents and catalysts in a domino Knoevenagel-Michael reaction. 


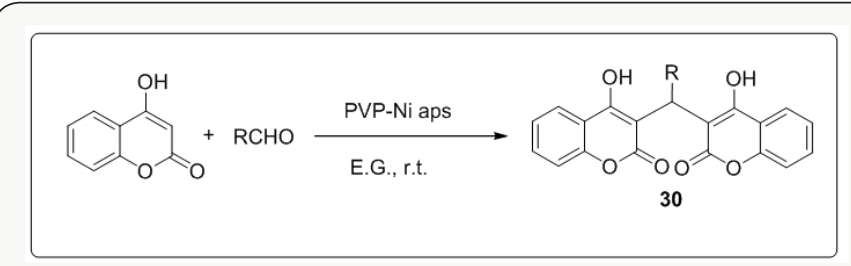

Figure 9

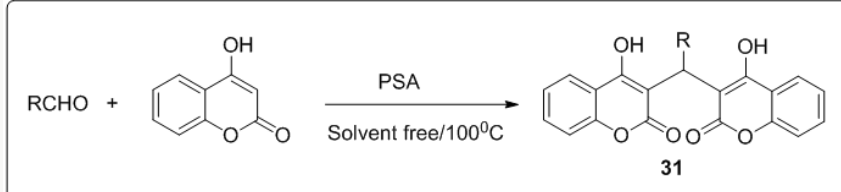

Figure 10

After extended optimization studies regarding the most important reaction parameters such as reaction time, temperature, and molar ratio of reactants, it was ascertained that the reaction between 4-hydroxy-coumarin and various benzaldehydes in the synthesized ILs proceeded smoothly at $40{ }^{\circ} \mathrm{C}$ in $3 \mathrm{~h}$, providing the desired biscoumarins in very satisfactory yields (up to 97\%) and high purity after simple workup [15] (Figure 11). The task-specific ILs were recycled and reused three times without a noticeable decrease in their catalytic activity. Moreover, the biodegradability potential of the synthesized ILs has been investigated by applying the biological oxygen demand (BOD-5) closed bottle test. The results indicated that organic carbon was biodegraded up to $59 \%$ within five days [16].

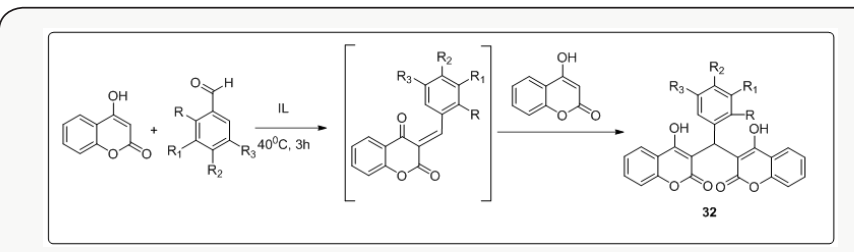

Figure 11

\section{Conclusion}

Biscoumarin have a prominent place in literature due to their pharmalogical and industrial applications, especially biscoumarin used as an anticoagulant. Large number of publications on biscoumrin forced us to made effort on biscoumarin. So, in this review we collected the solvent-free synthesis of bis-coumarins.

\section{References}

1. Guillemette A (1835) Justus Liebigs Ann Chem 14: 324.

2. Lehmann J (1943) The Lancet 241: 611.

3. Heubner CF, Sullivan WR, Stahmann MA, Link KP (1943) J Am Chem Soc 65: 2292 .

4. Sangshettia JN, Kokareab ND, Shindea DB (2009) Green Chem Lett Rev 2: 233.

5. Heravi MM, Nahavandi F, Sadjadi S, Oskooie HA, Bamoharram FF (2010) Green, one-pot, solvent-free synthesis of 1, 2, 4, 5-tetrasubstituted imidazoles using a Brønsted acidic ionic liquid as novel and reusable catalyst. Synth Commun 40: 498.

6. Khurana JM, Kumar S (2009) Tetrabutylammonium Bromide (TBAB): A Neutral and Efficient Catalyst for the Synthesis of Biscoumarin and 3,4-Dihydropyrano[c]-Chromene Derivatives in Water and Solvent-Free Conditions. Tetrahedron Lett 50: 4125-4127.

7. Heravi MM, Sadjadi S, Haj NM, Oskooie HA, Bamoharram FF (2009) Catal. Commun 10: 1643.

8. Khurana JM, Vij K (2010) Nickel Nanoparticles Catalyzed Knoevenagel Condensation of Aromatic Aldehydes with Barbituric Acids and 2-Thiobarbituric Acids. Catal Lett 138: 104-110.

9. Muratović S, Durić K, Veljović E, Osmanović A, Softić D, Završnik D (2013) Asian J Pharm Clin Res 6(3): 132.

10. Khalil T, Hannaneh H, Alireza K, Manouchehr M, Nosrat OM (2012) Synthesis of biscoumarin derivatives by the reaction of aldehydes and 4-hydroxycoumarin using ruthenium(III) chloride hydrate as a versatile homogeneous catalyst J Serb Chem Soc 77(4): 407-413.

11. Khurana JM, Vij K (2012) Nickel nanoparticles: A highly efficient catalyst for one pot synthesis of tetraketones and biscoumarins. J Chem Sci 124(4): 907-912.

12. Kiasat AR, Hemat AL (2013) Phospho sulfonic acid: a versatile and efficient solid acid catalyst for facile synthesis of bis-(4hydroxycoumarin-3-yl) methanes under solvent-free conditions. Res Chem Intermed 41: 873-880.

13. Tzani A, Douka A, Papadopoulos A, Evangelia A, Pavlatou, et al. (2013) Synthesis of Biscoumarins Using Recyclable and Biodegradable TaskSpecific Ionic Liquids. ACS Sustainable Chem Eng 1: 1180-1185.

14. Keating G, O Kennedy R (1997) Coumarins: biology, applications, and mode of action / edited by Richard O'Kennedy and R. Douglas Thornes. Chichester John Wiley \& Sons 23: 348.

15. Cooke D (1999) Studies on the Mode of Action of Coumarins at a cellular level. Dublin City University, Dublin, Ireland.

16. Egan D, James P, Cooke D, O Kennedy R (1997) Studies on the cytostatic and cytotoxic effects and mode of action of 8-nitro-7-hydroxycoumarin. Cancer Letts 118: 201-211. 
(C) (i) This work is licensed under Creative Commons Attribution 4.0 License

DOI: 10.32474/AOICS.2018.02.000139

\section{AOICS}

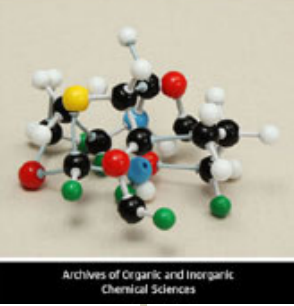

Archives of Organic and Inorganic

Chemical Sciences

Assets of Publishing with us

- Global archiving of articles

- Immediate, unrestricted online access

- Rigorous Peer Review Process

- Authors Retain Copyrights

- Unique DOI for all articles 